\title{
The revised Code of Practice for the Mental Health Act 1983
}

\author{
J.H.M. Crichton
}

On 19 May 1993 the Secretary of State for Health and Welsh Secretary laid before Parliament a revised Code of Practice of the Mental Health Act (MHA) 1983 (Department of Health, 1993). The Secretaries of State have a statutory responsibility (Section 118, MHA 1983) to produce revisions of the Code of Practice to reflect current good practice in mental health. This was to avoid lengthy and inflexible legislation in the MHA while making the provision for up to date guidance. The code is not legally enforceable but could be used as evidence of good practice in any legal proceedings. In the preface to the previous Code of Practice (HMSO, 1990) it was made clear that the code could be followed only "as resources permit". This reduces its impact and it is unclear whether a similar preface will feature in the revised code. The new Code of Practice has been in force from 1 November 1993 and while the form and spirit of the code is unchanged, there are important additions and changes of emphasis.

The previous code ran a stormy course before it was eventually published seven years after the MHA. The first draft was produced in 1987 by the Mental Health Act Commission (MHAC) and was roundly criticised by professional bodies for being too long and legally inaccurate (Royal College of Psychiatrists, 1986). The current code was produced by civil servants at the Department of Health and the Department has also produced this revision, consulting the "bodies primarily concerned", especially the MHAC who "played a major role" (Department of Health and Welsh Office, 1993). The revised code laid before Parliament underlines additions or changes and uses dots to show deletion from the current code. There are many additions, including a new chapter about patients' visitors, but there are very few deletions.

Most chapters have some minor changes which more accurately define terms or make clarifications; below are some of the more major changes under their chapter headings.

\section{Chapter 2, Assessment}

The chapter on assessment and admission specifies that a patient may be admitted because of danger to others even without danger to the patient's own health and safety. There is also encouragement to avoid misunderstandings and assumptions because of a patient's gender. social and cultural background, ethnic origin or because of physical illness, such as deafness. There is a new section suggesting hospitals introduce systems to monitor equality of assessment for these groups and keep a record of the ethnicity of detained patients. It is also stressed that there should be avallable trained interpreters.

\section{Chapter 9, Nurses' holding power (section 5(4))}

If a junior doctor does not attend within four hours of a patient being placed on a nurses holding power, then the consultant should attend.

\section{Chapter 15, Medical treatment}

The chapter about medical treatment and consent has been completely rewritten and gives practical, clear guidance consistent with that of the Royal College of Psychiatrists (Hirsch \& Harris, 1988) and taking account of the Lords decision in the case of $F$. $v$ West Berkshire Health Authority.

\section{Chapter 18, Patients presenting particular management problems}

It is made clear that restraining a patient by hooking clothing or tape should never be used. Staff are encouraged to make a balanced judgement between the patient's safety and autonomy. and must make clear in an individual care plan when restraint may be used and keep good records of any episode of restraint.

If a patient has been secluded for more than eight hours or cumulatively more than 12 hours over 48 hours then an independent review must be made by "a consultant or other doctor of suitable seniority".

The use of double-handed doors or similar devices to deter the "mentally frall elderly or people with learning disabilities" from wandering is allowed but patients who "persistently and 
purposely attempt to leave a ward . . . whether or not they understand the risk involved", should be considered for formal detention under the MHA.

\section{Chapter 19, Psychological treatments}

In this chapter there is clarification of the terms involved and particularly a clear definition of 'time out'.

Chapter 26, Visiting patients detained in hospital or registered mental nursing homes

This new chapter states the entitlement of detained patients to receive visitors whoever they may be with two general grounds for exclusion: restriction on clinical ground if the Responsible Medical Officer believes a visit to be untherapeutic; and on security grounds. If a decision is made to restrict visitors then this should be fully documented and any such decision made available to the MHAC. Hospitals are encouraged to facilitate regular visiting.

\section{Chapter 30, Children and young people under} the age of 18

This chapter has been updated, taking into account the 1989 Children Act and some recent case law.

\section{Conclusions}

The revised code is a fairly modest updating of good psychiatric practice as advocated by the Department of Health. The Secretary of State for Health has laid great weight on the new code because it clearly states criteria for compulsory admission (Department of Health, 1993). It is unlikely that psychiatrists, general practitioners or social workers were unaware of these criteria, especially since they had to work without any Code of Practice for seven years.

The clarification of terms and particularly the chapter on consent to medical treatment are helpful. It is unclear, however, how hospitals are meant to monitor racial and cultural equality in assessment of patients; this desirable aim may prove difficult in practice.

Although the revised code is more comprehensive and lengthier than its predecessor it is perhaps more notable in what has not changed. The Ashworth Inquiry (Department of Health, 1992) made important recommendations pertinent to all psychiatric practice, for instance guidance over the use of seclusion. The section on seclusion and related topics is largely unaltered; this may be because the current review of secure hospital provision is yet to fully report. There is no revision of Manager's Tribunals, which have been criticised as superfluous. There is no revision of guardianship orders which are likely to be replaced by the new supervised discharge arrangements. Also with the expectation of a Citizens Charter for the Mentally Ill, it may not be long before a fresh revision of the code is needed If not, as the MHAC have suggested, a revision of the MHA itself.

\section{References}

DEPARTMENT OF HEALTH (1992) Report of the Committee of Inquiry into Complaints about Ashworth Hospttal. London: HMSO.

- (1993) Press release 12 August. Legislation Planned to Provide for Supervised Discharge of Psychtatric Patients.

- \& Welsh Office (1993) Code of Practice. Laid before Parliament on 19 May 1993 Pursuant to Section 118(4) of The Mental Health Act 1983.

F v. West Berkshire Health Authority and Another (Mental Health Act Commission intervening) (1989) 2 All E.R., P. 545.

HMSO (1983) The Mental Health Act. London: HMSO.

- (1990) The Code of Practice. Mental Health Act 1983. London: HMSO.

HIRSCH, S.R. \& HARRIS, J. (1988) Consent and the Incompetent Patient: Ethics, Law and Medictne. London: Gaskell (Royal College of Psychiatrists).

THE ROYAL College of PSYCHIATRISTs (1986) Comments of the Royal College of Psychiatrists on the Mental Health Act 1983 Draft Code of Practice. Psychiatric Bulletin, 10. 194-195.

J. H. M. Crichton, Nightingale Research Scholar and Honorary Registrar in Psychiatry, University of Cambridge, Institute of Criminology, 7 West Road, Cambridge CB3 9DT 